\title{
"Tão longe tudo no tempo, e aqui tudo presente, tão vivo, me acorrendo ao bico da pena" ". Escrita autobiográfica e educação piauiense na obra de Cristino Castelo Branco (1892- 1931)
}

"Everything is so far in time, and here everything is present, so alive, reaching my quill pen". Piauí education and autobiographical writing in the work of Cristino Castelo Branco (1892-1931)

"Hasta ahora todo en el tiempo, y aquí todo está presente, tan vivo, corriendo hacia la pluma de mi pluma". Escritura autobiográfica y educación de Piauí en la obra de Cristino Castelo Branco (1892-1931).

Jane Bezerra Sousa Universidade Federal do Piauí (Brasil) http://lattes.cnpq.br/5086525916637041 https://orcid.org/0000-0002-5356-899X jane_bezerrasousa@yahoo.com.br

\section{RESUMO}

Este artigo tem como objetivo analisar a escrita autobiográfica e a educação piauiense por intermédio de uma pesquisa bibliográfica nas obras, Frases e Notas e Escritos de Vário Assunto, de autoria de Cristino Castelo Branco. Como referencial teórico de análise, este estudo fundamenta-se nos pressupostos dos seguintes autores: Brito (1996); Mendes (2012); Queiroz (2008); Ferro (1996); Lopes (2006, 2010); e Gomes (2004), entre outros. Como recorte temporal, designou-se o ano de 1892, data de seu nascimento, e o ano de 1931 como término, devido ao seu ingresso como Desembargador no Tribunal de Justiça do Estado do Piauí. As análises empreendidas neste trabalho levam a reflexões sobre a escrita de si, o constituir-se professor, os espaços escolares e os ideais educacionais piauienses durante a Primeira República, a partir da obra de Cristino Castelo Branco.

Palavras-Chave: Escrita de si. Pensamento Educacional. Educação na Primeira República.

\footnotetext{
${ }^{1}$ Frase retirada do livro Frases e Notas, de autoria de Cristino Castelo Branco.
} 


\begin{abstract}
This article aims to analyze the autobiographical writing and education in Piauí through a bibliographic search of the works, Frases e Notas and Escritos de Vário Assunto, by Cristino Castelo Branco. As a theoretical framework for analysis, this study is based on the assumptions of the following authors: Brito (1996); Mendes (2012); Queiroz (2008); Ferro (1996); Lopes (2006, 2010) and Gomes (2004), among others. As a timeframe, the year of 1892 was chosen for being the year of his birth, and the year of 1931 as the end, due to his entry as Judge in Piauí State Court of Justice. The analyzes comprised in this study lead to reflections on the writing of the self, becoming a teacher, school premises and educational ideals in Piauí during the First Republic, based on the work of Cristino Castelo Branco.
\end{abstract}

Keywords: Writing of the Self. Educational Thinking. Education in the First Republic.

\title{
Resumen
}

Este artículo tiene como objetivo analizar la escritura autobiográfica y la educación en Piauí a través de una investigación bibliográfica sobre las obras, Frases y Notas y Escritos de Vário Assunto, de Cristino Castelo Branco. Como marco teórico para el análisis, este estudio se basa en los supuestos de los siguientes autores: Brito (1996); Mendes (2012); Queiroz (2008); Ferro (1996); Lopes (2006, 2010); y Gomes (2004), entre otros. Como marco temporal, se designó el año 1892, la fecha de su nacimiento y el año 1931 como el final, debido a su ingreso como Juez en el Tribunal de Justicia del Estado de Piauí. Los análisis emprendidos en este trabajo conducen a reflexiones sobre autobiografia, convirtiéndose en maestro, espacios escolares e ideales educativos en Piauí durante la Primera República, basados en el trabajo de Cristino Castelo Branco.

Palabras clave: Autobiografia. Pensamiento Educativo. La educación en la primera república 


\section{Introdução}

Entramos em contato com as ideias de Cristino Castelo Branco pela primeira vez na biblioteca da Academia Piauiense de Letras (APL), durante as pesquisas relativas ao doutorado, oportunidade em que me deparei com um discurso dirigido às normalistas piauienses, referente ao período em que ele foi Diretor da instrução pública, o que chamou atenção por refletir todos os ideais de uma época sobre a imagem de ser professor, os métodos, os espaços escolares, as práticas escolares, o pensamento educacional e as políticas públicas educacionais.

Durante o período em que foi Diretor da instrução pública piauiense (1927-1930), ocorreu a expansão dos grupos escolares no Estado, daí porque recorri aos seus discursos e seus livros, os quais patentearam a grande contribuição que ele desempenhou na educação do Estado na Primeira República, antes mesmo de ser designado Desembargador no Tribunal de Justiça do Estado do Piauí. Como recorte temporal, estipulamos o ano de 1892, data de seu nascimento, e o ano de 1931 como término, devido ao seu ingresso como Desembargador no Tribunal de Justiça do Estado do Piauí.

No primeiro contato com a sua escrita, percebemos o quanto ela prende o leitor: cheia de minudências, de retratos da memória, contando um tempo, descrevendo as pessoas, os objetos e a própria vida. Com efeito, o autor revela suas vivências e as experiências de uma época, que passamos a sentir a partir de suas letras e dos sentimentos expressos nas ideias de quem amou intensamente a memória.

Por essa razão, muitas questões surgiram, as quais embasam esse texto: como foi a sua alfabetização, o ensino elementar e o secundário? Onde cursou o ensino superior? Como foi a sua vida profissional? Como pensava sobre a educação?

A partir de pesquisas, descobri que Cristino, além de advogado, foi professor, diretor da instrução pública, jornalista e desembargador. Penso que no Estado do Piauí, ele é mais lembrado por sua atuação na magistratura e não como docente, então, neste trabalho, faço um recorte de sua vida em função de seu percurso formativo como professor e diretor da instrução pública, revelando a sua contribuição para a educação piauiense, por meio de uma pesquisa bibliográfica que engloba as obras Frases e Notas, de 1957, e Escritos de Vário Assunto, de 1968.

Ademais, engendro um entrecruzamento entre os seus escritos autobiográficos e os autores piauienses que abordaram a história da educação, a exemplo de: Brito (1996); Mendes (2012); Queiroz (2008); Ferro (1996); Lopes (2006), entre outros. Também como aporte teórico da temática autobiografia e história da educação, o estudo é ancorado em Gomes (2004).

\section{Escrita de si e os espaços escolares}

No livro Frases e notas, de 1957, no capítulo intitulado Notas retrospectivas, Cristino Castelo Branco realiza o que compreendo como uma escrita de si.

A escrita auto referencial ou escrita de si integra um conjunto de modalidades do que se convencionou chamar produção de si no mundo ocidental. Essa denominação pode ser mais bem entendida a partir da ideia de uma relação que se estabeleceu entre o individuo moderno e seus documentos. (GOMES, 2004, p. 10)

Penso que Cristino Castelo Branco tentou criar a sua escrita como Gomes (2004) denomina teatro da memória, ou seja, "um espaço que dá crescente destaque à guarda de registros que materializam a história do indivíduo e dos grupos a que pertence" (GOMES, 2004, p.11). Exemplo disso pode ser contemplado quando o autor retrata a história de Clodoaldo Freitas e, igualmente, na obra Homens que iluminam. 
Ao que parece, com sua escrita, desejava oferecer ao mundo em que vivia um sentido especial acerca de sua trajetória, daquilo que ele achava que merecia ser lembrado. Nessa perspectiva, suponho que ao escrever em seu livro aspectos de sua vida, [...] Cristino tinha consciência de que seus escritos registravam uma memória que sobreviveria à sua história e à dos outros. Seus textos constituem fases específicas de uma vida, como o nascimento, o casamento, a profissão - o que podemos cognominar de "múltiplas temporalidades" (GOMES, 2004, p.18).

Nesse ensejo, introduz as notas retrospectivas afirmando que achava chegar muito cedo em um mundo muito novo, e que daqui a trezentos anos, o mundo estaria melhor, definindo-se como conformado à época em que viveu, tendo em vista as situações impostas por Deus, daí porque rememoraria a sua vida.

A escrita autobiográfica e a sua relação com o campo da história da educação tem crescido, ao empregar as fontes visando à análise de determinada época. No Piauí, Lopes (2006, p. 12) faz interessante observação ao mencionar que as escritas autobiográficas têm sido desenvolvidas especialmente por homens, "sinal de que a prática de escrever sobre si e suas experiências, numa exposição de sua trajetória, era indício de importância pública de sua posição no mundo".

O referido autor faz essa asserção baseando-se no fato de que de um total de 33 textos autobiográficos, 28 foram escritos por homens e apenas cinco, por mulheres. Uma hipótese é que aqueles ocupavam os espaços literários e de acesso aos meios de publicização de seus escritos, considerando o período entre 1939 e 2005.

Cristino nasceu em 24 de julho de 1892, na Rua do Fio, hoje Rua Coelho Rodrigues, Teresina - PI. Era filho de Joaquim Ferreira Castelo Branco e Adelina Couto Castelo Branco. A mãe, falecida em 30 de junho de 1905, quando ele contava 13 anos de idade, é assim descrita: "mulher ainda nova, simpática, inteligente, cheia de graça e vivacidade, era, pela verve de que dispunha, o encanto das rodas e das palestras que tomava parte" (CASTELO BRANCO, 1957, p.122).

Sobre a ausência pai, que foi guarda livros, comerciante e funcionário público municipal, e faleceu em 15 de novembro de 1933, aos 72 anos de idade, denota ter sido uma perda profunda, relatada nos versos: "parou, findou-se para sempre a lida, de quem me era no mundo luz potente a iluminar os píncaros da vida". (CASTELO BRANCO, 1957, p.122).

Quando criança, empinava papagaio, jogava pião, ia à novena, subia nos muros e nas árvores, passeava pelas ruas e praças, montava em carneiros, gostava de ouvir as palestras entre seu pai e amigos. Em suas lembranças, estão presentes o tabuleiro de doces de Agostinha e o embarque do $35^{\circ}$ Batalhão para Canudos, na beira do rio, além das noites de São João e São Pedro. As doenças, como sarampo, catapora ou gripe muito forte, na época de sua infância, eram cuidadas pelo Dr. Areolino, médico da família: "estrábico e circunspecto, olhando de banda, muito aprumado no seu fraque de alpaca, o mesmo, ou idêntico, com que discursou eloquentemente no primeiro dia do século" (CASTELO BRANCO,1957, p. 125).

Fez os seus estudos elementares nas aulas primárias de Sinhá Borges, em uma sala ampla e arejada na Rua Paissandu. Relembra a tabuada e as lições de leitura em Felisberto Carvalho. Maria Emígdia Castelo Branco, sua professora, foi conhecida por Sinhá Borges, conforme Ferro, (1996), esta teria sido responsável pela orientação das meninas no Colégio Nossa Senhora das Dores, escola fundada em 1882, sob a direção de Miguel de Sousa Borges Leal Castelo Branco, a partir de 1887, por problemas de saúde do Diretor assumiu o Professor Marcelino Ferreira Borges Castelo Branco.

Quando de sua morte, o colégio foi adquirido por Antonio de Sousa Rubim. A instituição funcionava em regime de internato e externato, recebendo meninos e meninas. Ao que parece, após o fechamento da escola, Sinhá Borges continuou ministrando aulas de ensino elementar - era sua prima em quinto grau, o que requisitava maior respeito do aluno, que a chamava de tia e tomava a benção. 
Em seguida, frequentou, na antiga Rua Grande, o Colégio do Luís Sabino, em um casarão da esquina, que na época era famoso em todo o Piauí, pela disciplina e a severidade dos castigos.

Tive a desdita de ver e ouvir alguns pais, matriculando os filhos, dizerem em cruel recomendação: 'Seu Luís, meta o pau'. Era essa infelizmente a mentalidade pedagógica da época, o que escusa de muito a dureza do professor, que aliás sempre me tratou humanamente, com brandura e suavidade. Verdade é que meu pai, campeão do bom senso, e iluminado pelo coração, nunca fez a tal recomendação (CASTELO BRANCO, 1957, p.125).

Aos onze anos, iniciou o preparatório do Liceu Piauiense. Ao estudar a Gramática de José Ribeiro e os trechos do livro Iracema, de José de Alencar, contou com os professores: Casusa Avelino, Otávio Falcão, Acrísio Veras, Higino Cunha, entre outros. Dessa forma, em 1906, já com catorze anos, concluiu os dez preparatórios exigidos para a matrícula na Faculdade de Direito.

Como Liceísta, ${ }^{2}$ esteve no desembarque de Afonso Pena. No Piauí, em suas memórias, seus professores são notabilizados, a exemplo de Antônio Freire:

meu antigo professor de geometria no Liceu Piauiense. Operoso e inteligente, interessou-se bastante pelas coisas do ensino público, para o qual expediu importante regulamento que vigorou durante vários anos, foi o fundador da Escola modelo e da Escola Normal em Teresina (CASTELO BRANCO, 1957, p.153).

A partir de suas memórias, temos em contato com vários sujeitos, como Antonino Freire, Miguel Rosa, Higino Cunha, pois à medida que recorda suas experiências, manifesta diferentes vivências, como abona Lopes (2006, p. 23):

Os escritos autobiográficos possibilitam, por fim, uma visão heterogênea $\mathrm{d}$ atrama dos processos formativos e nos ajudam a repensar o processo de escolarização e as ações educativas a partir dos diferentes olhares e experiências. Diversos sujeitos se cruzam nessas memórias, fazendo-nos reconhecera pluralidade do mundo e de suas reconstruções.

Miguel Rosa foi seu professor de História do Brasil; Higino Cunha, de Inglês - antigo discípulo de Tobias Barreto, um dos expoentes da vida cultural do Estado, sobre quem assim se referiu: "Não sabe ainda se envelheceu, porque as ansas, os anelos, as revoltas magnificas e trepidantes que fazem a beleza e a eternidade da vida, estão com ele dentro do coração. Não sabe ainda se morrerá, porque não morre a glória verdadeira dos homens as suas marcas" (CASTELO BRANCO, 1957, p. 169).

Exaltava os homens inteligentes do Piauí à época: Abdias Neves, Antonino Freire, Miguel Rosa, Clodoaldo Freitas, Higino Cunha, Elias Martins e Manuel Lopes Correia. Havia, naquele período, uma luta entre a maçonaria e o clero. Entre os estudantes, "o preconceito de ser católico equivalia a ser burro, pois os homens tidos como mais inteligentes se diziam ateus e achincalhavam os padres" (CASTELO BRANCO, 1957, p. 130).

\footnotetext{
${ }^{2}$ Como era chamado o estudante do Liceu Piauiense.
} 
Tal aspecto leva a pensar sobre a constituição das relações sociais, construídas, em sua maioria, nos espaços escolares e transferidas para outros ambientes, "dando-nos a pensar sobre o lugar da escola, da construção dessas tramas de sociabilidade e na constituição de um capital social importante na posterior vida profissional dos estudantes" (LOPES, 2006, p. 23).

Assim, em 5 de abril de 1907, embarcou para Recife, na companhia de Wladimir Abreu, Hugo Napoleão e Raul Martins, que também iniciariam o curso de direito. A viagem era considerada demorada, porquanto iam de trem até Caxias, no Maranhão, de onde seguiam de gaiola, O Itapecuru, a fim de aguardar em São Luís o navio do Loide. Chegou a Recife no dia 16 de abril, após onze dias de viagem: "uma grande cidade, com as suas pontes, as suas ruas de sobrados, cheias de gente, o comercio considerável, o movimento do porto, os professores ilustres, o meio acadêmico saturado das chamadas ideias novas que atordoavam os calouros" (CASTELO BRANCO, 1957, p. 132).

Em consonância com Ferro (1996), o Piauí, nessa época, ainda não possuía estradas de ferro, e o deslocamento para o Maranhão era realizado usando a linha férrea de Cajazeiras (hoje Timon), via Caxias. Tais viagens ocorriam porque não havia cursos superiores no Estado, daí os estudantes tinham de emigrar para outras cidades, nomeadamente:

Recife, Pernambuco, principalmente para a Faculdade de Direito, onde vários piauienses se bacharelaram ou para o Seminário de Olinda;

Salvador, na Bahia, preferentemente em busca de cursos na área de saúde, como Medicina e Farmácia;

São Luís do Maranhão, para cursar o Seminário das Mercês;

Rio de Janeiro-para os cursos de Medicina ou curso de engenharia na Escola politécnica da antiga capital do País. (FERRO, 1996, p. 96)

A Faculdade de Direito, em Recife, funcionava em um velho casarão na Igreja do Espírito Santo, na Praça Dezessete. Criada em 1827, teve sede em Olinda, até 1854. "Levei muito a sério os estudos da faculdade, tendo sido, por isto mesmo, a nota mais alta numa turma de cento e tantos alunos, onde havia gente de todos os Estados do Brasil" (CASTELO BRANCO, 1957, p. 133).

Em suas lembranças, Cristino mostrou o cotidiano da Faculdade de Direito, onde teve de redobrar os estudos em função de os colegas lhe provocarem medo. Dessa forma, foi aprovado por distinção em Direito Romano e Filosofia do Direito, sendo elogiado pelo professor Laurindo Leão; assim como em Direito Civil, sob responsabilidade de Henrique Milet: "sem dúvida, não seria eu, pobre rapazelho do Piauí, o aluno mais inteligente e preparado da turma, mas certas qualidades de exposição e um acentuado espirito de síntese davam-me a primazia" (CASTELO BRANCO, 1957, p. 134).

Ao escrever sobre si mesmo, traz as atividades que fazem parte de sua própria definição. Logo, sua identidade é construída marcadamente por sua atuação na esfera pública. Cristino morou em várias repúblicas em Recife, sendo a última na Rua Augusta, oportunidade em que manteve contato com Lucidio Freitas, Nogueira Tapeti, entre outros piauienses e maranhenses. Descreveu as repúblicas desse período como centros de convivência onde havia harmonia, estudo e novas ideias, e quase todos os estudantes preferiram morar dessa forma, porque além de se sentirem mais à vontade, formavam laços de amizade.

Aliás, aponta que se encontravam muitos estudantes piauienses naquela época em Recife, e muitas vezes foram auxiliados por Olímpio Costa, também piauiense. Lembrou, ainda, as receitas grátis para os estudantes, emitidas pelo médico Otávio de Freitas, pelo dentista Marcelino Sampaio Castelo Branco, ambos conterrâneos.

Aos dezenove anos, Cristino termina o curso, colando em grau em 11 de dezembro de 1911, no edifício da faculdade, na Praça Adolfo Cirne. O orador de sua turma foi Barreto Campelo, e o paraninfo, Gervásio Fiovaranti; como amigos, citou Francisco Cavalcanti Pontes 
de Miranda e Bráulio Cavalcanti, e alguns piauienses, como: Raimundo Cunha, Nogueira Tapeti, ${ }^{3}$ Afonso Soares, Corinto Andrade, Wladimir Abreu, Esmaragado de Freitas e Nilo Brito.

Ao concluir o curso, retornou à terra natal, no início do século XX. No Piauí, uma grande gama de bacharéis atuava de forma ativa na imprensa local: "bacharel que não escrevia em jornal e não fazia discurso, suspeito ficava de burrice" (CASTELO BRANCO, 1957, p. 139).

Ao regressar, colaborou no Piauí, jornal que pertencia ao Partido Republicano Piauiense, e no Diário do Piauí, dirigido por Simplício Mendes. Sua escrita abordava vários assuntos, entre os quais chamou atenção a Reforma Rivadavia Correia. A propósito, percebo aqui o seu interesse pelo tema educação, especialmente sobre o pensamento educacional e as políticas públicas vigentes. Sua escrita leva à reflexão para além de seu relato autobiográfico, trazendo a história do tempo em que viveu.

Parece que o autor do relato autobiográfico trata de algo "que não se reduz meramente à sua existência pessoal, mas que pode servir, inclusive, para a construção de uma história da cidade ou do Piauí que considere a visão do autor, tido como um sujeito marcante dessa história" (LOPES, 2006, p.20).

Segundo Camilo Filho (1986), Cristino Castelo Branco era destaque nas letras piauienses ao lado de outros nomes, como: Higino Cunha, Clodoaldo Freitas, Anísio Brito, Abdias Neves e Lucídio Freitas.

Dessa maneira, ingressou no magistério como lente de francês, no Liceu Piauiense e na Escola Normal, tendo ensinado, juntamente com o seu antigo professor, Acriso Veras. Assim, relembra que neste mesmo ano, foi nomeado Anísio Brito; além disso, inicia na advocacia, em 1917, exercendo juizado de direito em Brejo, no Maranhão; posteriormente, regressa a Teresina, em 1919, continuando sua colaboração no Jornal O Piauí. Ademais, em 1921, inicia os serviços como advogado da prefeitura. O corpo docente da Escola Normal, conforme Piauhy (1928), era constituído da seguinte forma:

\author{
Portuguez - Professor Martins Napoleão e Firmina Sobreira que \\ substituía o lente efectivo professor Leopoldo Cunha. \\ Francez - Doutores Christino Castelo Branco e Audemaro Motta \\ Arithmetica e Algebra - Doutores Area Leão e Luís Mendes Ribeiro \\ Gonçalves \\ Geometria - Doutor A.C. Vieira da Cunha \\ Desenho- Álvaro Freire \\ Geografia - Doutor A. Celestino Franco de Sá \\ História Universal e do Brasil - Doutor Anísio de Brito Mello \\ História Natural - Doutor M. Sotero Vaz da Silveira \\ Pedagogia - Lélia de Moraes Avelino \\ Música - Dona Firmina Sobreira Cardoso \\ Trabalhos de Agulha - Dona Maria de Lourdes Martins Rêgo
}

Vale ressaltar que em 1917, ocorreu a fundação da Academia Piauiense de Letras, e em 1918, do Instituto Histórico e Geográfico do Piauí, o que demonstra o interesse pelas letras e pelos estudos históricos-socias, de acordo com Ferro (1996).

Cristino casa-se com Dulcila Santana Castelo Branco, em 17 de janeiro de 1914. Em 1925, retorna às aulas no Liceu e na Escola Normal, lecionando Francês e Instrução Moral e Cívica. Em 1 de janeiro de 1927, assume o Cargo de Diretor Geral da Instrução Pública, onde permanece até 4 de outubro de 1930.

\footnotetext{
${ }^{3}$ Benedito Francisco Nogueira Tapeti.
} 
Durante a sua gestão como Diretor da Instrução Pública, foi realizado o centenário do ensino primário no Brasil, oportunidade em que se cumpriu um grande evento em Teresina, com início às sete horas da manhã, reunindo todas as escolas no Grupo Demóstenes Avelino, de onde seguiram para a Praça Marechal Deodoro. Em frente à Escola Normal, praticaram exercícios de ginástica sueca e cantaram o hino do primeiro centenário do ensino primário, como se vê na programação:

As 10horas na Egreja do Amparo foi celebrada uma missa pelo padre Zaul pedreira. As 14horas haverá uma sessão cívica no salão da nobre da Escola Normal em que fallarão as professoras Firmina Sobreira, Lélia Avelino e Maria Dina Soares. No cinema Olympia às 17h12 haverá vesperal a criançada. Terminarão as festas com um chá dançante as 19horas na Escola Normal. (ENSINO...1927, p. 1)

Nessa época, foram criados vários grupos escolares, tanto na capital quanto no interior, aumentando consideravelmente as matrículas. Sobre essa questão, Humberto de Campos, em 1928, visitando os estabelecimentos públicos em Teresina teria mencionado:

se os homens não adorassem a mulher, honrando nela a mãe, adorá-la-iam na santidade das mestras. Esta casa honra a mulher piauiense, patenteando a sua inteligência, a sua cultura, a sua dedicação, as qualidades e virtudes, em suma, que fazem dela- mãe ou esposa, filha ou educadora- o encanto e a glória da vida. (CASTELO BRANCO, 1957, p. 161)

Durante a gestão de Cristino Castelo Branco na Diretoria de Instrução Pública, ocorreu o processo de interiorização dos grupos escolares: "O ano de 1928 é marco do processo de interiorização do modelo grupo escolar, com a criação desse tipo de escola nos municípios de União, Livramento (atual José de Freitas), Barras, Campo Maior, Picos e Floriano" (LOPES, 2010, p. 101).

O susodito autor, ao referir-se ao discurso de Cristino na inauguração do Grupo Valdivino Tito, em 1929, na cidade de Teresina, assim se pronuncia:

Esse discurso procurou unir a reforma de 1910 visava marcar como modernidade escolar: professora normalista e grupo escolar. Incorporava, contudo, os desencantos que o governo tinha coma professora normalista e que ficou patente na crise de 1922, quando se declarou a insuficiência da feminização do magistério e cogitou-se a necessidade do celibato. Por isso o prédio e os recursos didáticos aparecem coo dependentes da competência das professoras. Como boas professoras independem de prédios e recursos didáticos, a existência destes era um luxo que não podia ser extraviado. O discurso de Cristino Castelo Branco procurava demonstrar que o governo cumpria seu papel e que a responsabilidade sobre os destinos da escola inaugurada era das professoras (LOPES, 2010, p.101-102).

Relatou, ainda, a presença e importância de Firmina Sobreira no processo de consolidação da Escola Normal em Teresina, a convite de Antonino Freire, introduzindo novos modelos, novos programas e nova orientação pedagógica: "tipo completa de educadora. Vocação decidida de mestra. Era a escola Sua vida, a sua alma, a sua razão de ser. Logo que a deixou, morreu" (CASTELO BRANCO, 1957, p. 163). É oportuno relembrar que após a fundação da Escola Normal em Teresina, a partir de 1910, 
para a implantação definitiva do ensino normal, o governo solicitou a vinda da professora normalista Firmina Sobreira, formada pela Escola Estadual do Estado do Maranhão, que se aplicou a consolidação do curso normal e é, pela sua dedicação a causa, considerada como uma das principais responsáveis pela continuidade da formação de professores" (FERRO, 1996, p. 106)

Fato interessante durante a sua gestão como Diretor da Instrução Pública é que em 13 de julho de 1928, foi a reivindicação da professora Joana de Abranches Saraiva - devido um projeto que foi submetido à Câmara para diminuir os salários de professores - que reclama que isso não poderia ser possível, uma vez que, os vencimentos que recebiam já eram diminutos para as suas funções: "É provável que uma das causas do baixo nível de preparo de parte dos professores encontre nesta situação de desvalorização salarial uma das suas principais motivações" (FERRO, 1996, p. 92).

Como visto, Cristino foi professor no Liceu e na Escola Normal, e Diretor da Instrução Pública. Vale salientar sua atuação ao assumir, em 30 de outubro de 1917, a cadeira de membro da Academia Piauiense de Letras, tendo como patrono Antônio Borges Leal Castelo Branco.

Em 4 de outubro de 1930, foi procurado, ao amanhecer, pela porteira do Grupo Escolar Teodoro Pacheco, para saber se abriria a instituição, pois o Governador estava preso e teria dito que poderia deixar o grupo fechado e aguardar a nomeação de um novo diretor da instrução pública. A perda do cargo não o amedrontou, então intensificou os serviços de advocacia. Foi também professor de direito civil na recém Faculdade de Direito do Piauí, cuja ata assinou em 14 de abril de 1931, tendo deixado essa função para assumir a vaga de Desembargador do Tribunal de Justiça, em 4 de novembro de 1931. Cristino era contra a acumulação de cargos, por achar que o magistério exigia muita dedicação do professor.

Considero um erro grave, a acumulação permitida pela constituição federal, das funções do magistério e da magistratura, cada qual mais séria, mais alta, mais absorvente. Condenando esta e outras acumulações, Pontes de Miranda observa que a constituição foi feita pelos acumuladores. $\mathrm{O}$ magistério não é apenas a hora de aula, como pensam muitos. Em alguns países é o tempo todo. (CASTELO BRANCO, 1957, p. 176)

\section{Educação piauiense no pensamento de Cristino Castelo Branco na Primeira República}

Neste tópico, procuro promover uma análise sobre o pensamento educacional de Cristino Castelo Branco, a partir de seus discursos, considerando que a sua atuação efetiva na docência ou como gestor educacional concentrou-se na Primeira República do Brasil, o que influenciou sobremaneira as suas ideias.

Como aduz Souza (2008), existe uma centralidade atribuída aos republicanos quanto à educação - marcada pelo imaginário de modernização educacional - ancorada na integração social e na forma cívico-patriótica, afirmação da nação, difusão dos elementos das ciências.

Essas ideias permearam o pensamento de Cristino Castelo Branco, estando presentes em seus discursos e escritos, ao defender a escola para o povo, principalmente no sentido elementar, quando clama pelo fim do analfabetismo, inferindo que só existe liberdade com a instrução, como se pode confirmar abaixo:

Precisamos educar, instruir o povo, para realizar a república. É este o problema máximo da vitalidade nacional. Se o povo não sabe ler e se o 
analfabeto não pode votar como falar em república, como falar em democracia, como querer de verdade representantes do povo soberanamente eleitos? Além de que como observa Araújo Costa o homem só é verdadeiramente livre quando é instruído, pois do contrário estará sempre na dependência de outrem. (CASTELO BRANCO, 1928, p. 92)

E assim, concebendo o modelo educacional proclamado pelos republicanos, menciona em seu discurso o papel cívico da professora no processo de implantação da educação popular. Para Souza (2008), nos anos que seguiram a Proclamação da República, os governos estaduais buscaram executar reformas de instrução pública com o intuito de promover a educação popular, consubstanciada em estabelecer a obrigatoriedade e gratuidade do ensino primário. É o que se nota em outro discurso da mesma revista, datada de 14 de janeiro de 1928:

Gentilíssimas professoras, o diploma que acabastes de receber não é apenas a recompensa dos vossos esforços durante quatro anos de estudos nesta casa, é também um encargo um título de responsabilidade, porque de hoje em diante sois mestras e ser mestra é das coisas mais altas, mais nobres, mais difíceis, mais espinhosas que há. Aprendestes na aula de pedagogia que o professor primário de hoje não é mais o de alguns anos atrás, que ensinava apenas a ler, escrever e contar à luz da palmatória e de castigos grotescos, numa verdadeira degradação moral que nos aviltava e nos deprimia aos olhos da cultura humana. A escola pública actual, radiosa iluminada, interessantíssima, prende a seduz a alma da criança que vai para ella contente, satisfeita como para uma festa a linda festa da inteligência o carinho, o amor, a dedicação, a bondade, a inteligência, o preparo, o civismo da professora substituíram a athmosphera de terror que dominavaos antigos estabelecimentos. (CASTELO BRANCO, 1928, p. 146)

O discurso de Cristino corrobora o pensamento de Sousa (2015), ao analisar as concepções de ser professora no Piauí entre 1922 a 1928, a partir das notas de jornais e das mensagens governamentais, onde mostra que no início da República, a profissão era muita desvalorizada, mas modificações advindas do projeto republicano de progresso que visava à educação popular impulsionaram a reabertura da escola normal, a criação de grupos escolares, gerando debates entre clericais e anticlericais. $O$ resultado disso foi a "institucionalização da profissão professora normalista como missionária, mãe e salvadora da pátria, além de estar coberta de reconhecimento social e uma áurea gloriosa, o que escondia por vezes, a falta de reconhecimento econômico" (SOUSA, 2015, p.83).

Os alunos não são mais autômatos, instrumentos passivos sem brio, sem alma, sem dignidade, nas mãos do mestre, cada um deles é uma individualidade que se procura despertar é um caráter em via de formação é um cidadão cuja inteligência e cujo civismo se vão carinhosamente cultivar. D'ahi não haver profissão que exija maior devotamento e maior dedicação que o magistério. Já houve quem optasse que ser professor apenas para receber o ordenado, para ter um emprego, sem amor ao officio sem interesse pela sorte dos alunos sem a compreensão exacta, perfeita, luminosa dos seus deveres e da sua responsabilidade, sem a consciência nítida da sublimidade da sua missão social é um crime, uma torpeza e uma falta absoluta de patriotismo. (CASTELO BRANCO, 1928, p. 147) 
É possível vislumbrar as conclamações de amor ao magistério como uma missão social e patriota. As ideias que permeiam o discurso do Professor Cristino mostram a noção de ser professor no início do século XX, e já conduz o aluno como centro:

O preceptor deve a escola toda sua inteligência, toda sua energia, toda sua atividade, deve estudar sempre. O professor que não estuda não é professor. Estudar não só as disciplinas que ensina, os methodos a adoptar os progressos da pedagogia senão também da sociedade o meio em que vive e sobretudo os discípulos, os alunos confiados a sua guarda, A criança dizem os pedagogos é um motivo constante de observação e de estudo para a perfeita aplicação de métodos e processos capazes de formação de uma individualidade completa, lógica e consentânea com a vida moderna. [...] A escola primária, na sua concepção hodierna, baseada no método intuitivo, nacional, concretizando o mais possível o ensino para aproveitar a curiosidade natural da infância é uma das coisas mais sugestivas e mais fulgurantes que conheço. Por mais completa por mais perfeita porem que seja a sua organização por melhor e mais admirável que seja o methodo adoptado, ella a escola nenhum proveito, nenhum resultado dará se o mestre inteligente e culto não estiver. A altura da sua missão não for apaixonado pelo seu officio não fizer da sua cathedra um sacerdócio. (CASTELO BRANCO, 1928, p.147-148).

Esse discurso do Diretor Cristino Castelo Branco, publicado no ano de 1928, reflete muito das ideias disseminadas no fim do século XIX e início do século XX, para justificar a mulher no ensino primário, invocando, ainda, a missão, o sacerdócio, a vocação e a salvação do analfabetismo, como se ratifica em Queiroz (2008, p. 93): “Assim muitos dos atributos associados à ideia da professora primária, como de ter um trabalho que é sacerdócio e missão, o celibato".

e para o magistério para o professorado primário nenhuma dúvida mais existe sobre a superioridade do sexo feminino. A pre excellencia da mulher como educadora da infância disse Ruy Barbosa é um facto de evidencia universal. E depois de mostrar a sociedade, abundantemente, no seu notável parecer apresentado em 1882 a câmara dos deputados que a mulher interioriza em si o instinto da educação cita as palavras de madame de Maintenon que observou certa vez 'Qualquer poder de bons conselhos conseguira educar uma criança dos dez anos em diante mas até essa idade não há agudeza de preceitos que baste é mister, gênio e com este embaraço, os homens não se sabem haver' (CASTELO BRANCO, 1928, p.148).

Acerca do papel da mulher na sociedade piauiense, assunto tão reproduzido nos discursos de Cristino, busco em Queiroz (2008) suporte para a análise, quando afirma que certo cientificismo marcou a geração pós Higino Cunha e Clodoaldo Freitas, ambos contemporâneos de Cristino, mas com certos traços positivistas, sendo que nessa época, ainda havia interferência da igreja na sociedade piauiense, daí isso hipoteticamente resultar no ideal de professora como "virgem, missionária e beata, além de asséptica" (QUEIROZ, 2008, p. 94).

Para a supracitada autora, o espaço de trabalho no Piauí, no início do século XX, ainda era bastante reduzido, o que resultava no fato de a mulher transitar do lar para a igreja, sendo 
outra alternativa a Escola Normal, com a sua consequente atuação no exercício do magistério primário. Por sua vez, o ensino secundário ainda era procurado exclusivamente pelo sexo masculino. A partir daí, surgiu um "modelo de mulher esclarecida, porém esposa e mãe, especialmente rainha do lar" defendido pelos intelectuais do fim do século XIX (QUEIROZ, 2008, p. 96). A afirmação abaixo ilustra que o papel de professora era um dos permitidos socialmente, por ser aliado das questões maternas:

A mulher política a mulher eleitora, a mulher deputada como a querem fazer a actualmente é a mulher fora de sua finalidade. A mulher nasceu para ser mãe e professora. Porque ser mãe é desdobrar fibra por fibra o coração, ser professora é fazer do coração a fonte de sabedoria. E nessas duas tarefas por serem sobremodo absorventes não devem ser exercidas ao mesmo tempo por uma (CASTELO BRANCO, 1928, p. 149)

O discurso de Cristino reflete o pensamento da época, em que a mulher era apropriada para exercer o magistério primário, onde os ideais de missão, vocação e sacerdócio permeavam a profissão docente. Finalmente, reconhece: "ao magistério a mais útil e a mais patriótica das profissões toda a vossa inteligência e todo vosso entusiasmo, toda vossa mocidade, todas as vossas virtudes que são muitas são altas que são nobres" (CASTELO BRANCO, 1928, p. 148).

\section{Considerações Finais}

Este trabalho traz a vitrine historiográfica atinente aos escritos autobiográficos de Cristino Castelo Branco, presentes em sua obra - ele que foi professor, diretor de instrução pública, desembargador, jornalista e escritor -, além de demonstrar a análise de parte de seus escritos e as reflexões sobre o seu pensamento quanto à área educacional. Ao realizar a leitura, é possível identificar, na escrita de si, experiências de sua vida pessoal, como a infância, o casamento, as lembranças dos pais, dos familiares e do cotidiano da cidade.

Com efeito, a educação é descrita desde o ensino elementar: por intermédio das aulas de Sinhá Borges; do livro de Felisberto de Carvalho; das regras do professor Luís Sabino, no Colégio; das lembranças como aluno do Liceu; de seu ingresso na Faculdade de Direito, em Recife. Em todos esses momentos, Cristino lança uma memória coletiva, revelando fatos do cotidiano, denotando aspectos de sua identidade, bem como sinalizando a sua admiração por seus professores.

Em seguida, o artigo desvela Cristino como professor do Liceu e da Escola Normal, aliado à sua experiência como Diretor da Instrução Pública no Piauí, em um período em que o Estado vivia a expansão dos grupos escolares e a construção de prédios escolares.

Outrossim, descortina uma reflexão sobre a mulher no magistério primário, corroborando o pensamento educacional da época, onde os ideais de vocação, missão e sacerdócio permeavam o magistério feminino. Considero oportuno que os estudos sobre a obra e o pensamento de Cristino Castelo Branco sejam ampliados em outros trabalhos, porquanto enriquecerão a história da educação piauiense, estimulando novas pesquisas e novas reflexões.

\section{Referências}

BRANCO, Cristino Castelo. Escritos de vário assunto. Rio de Janeiro: Rongetti, 1968.

BRANCO, Cristino Castelo. Frases e notas. Rio de Janeiro: Rongetti, 1957.

BRANCO, Cristino Castelo. Homenagem às normalistas. Revista da academia Piauhyense de Letras, Teresina, PI, ano XI, n.12, Typografia D’o Piauhy, p.148, 1928. 
CAMILO FILHO, José da Silveira. Pequena História do Piauí. Teresina: Comepi, 1986.

ENSINO Primário. Imprensa, Teresina, PI, 15 out. 1927.

FERRO. Maria do Amparo Borges. Educação e sociedade no Piauí republicano. Teresina, PI: EDUFPI, 1996.

GOMES, Ângela de Castro. Escrita de si, escrita da história. Rio de Janeiro: FGV, 2004.

LOPES, Antônio de Pádua Carvalho. A escrita autobiográfica; os documentos pessoais e a história da educação. In: NASCIMENTO, Francisco Alcides do; VAINFAS, Ronaldo. História e historiografia. Recife: Bagaço, 2006. p. 11-29.

LOPES, Antonio de Pádua Carvalho. Das Escolas Reunidas ao Grupo Escolar: A Escola como repartição pública de verdade. In. VIDAL, Diana Gonçalves (Org.). Grupos Escolares: Cultura Escolar primária e Escolarização da Infância no Brasil (1893-1971). Campinas, SP: Mercado das Letras, 2010.

MENDES, Iweltman. História da Educação Piauiense. Sobral: Egus, 2012.

PIAUHY, Governador, 1925-1928 (Matyas Olympio de Melo) Mensagem apresentada à Câmara legislativa, pelo Exmo. Sr. Governador do Estado, em 01 de junho de 1928. Theresina: Piauhy, 1928.

QUEIROZ, Teresinha. Educação no Piauí (1880-1930). Imperatriz, MA: Ética, 2008.

SOUSA, Jane Bezerra de. Ser e fazer-se professora no Piauí no século XX: a história de vida de Nevinha Santos. Uberlândia, MG: Edufu, 2015.

SOUZA, Rosa Fátima de. História da organização do trabalho escolar e do currículo no Século XX (ensino primário e secundário no Brasil). São Paulo, SP: Cortez, 2008. 320P. (Coleção: Biblioteca Básica de História da Educação Brasileira, v. 2). 